\section{What is the rare but \\ well-documented cause of this recurrent chest infection?}

\section{Case history}

A 61-year-old female presented with a history of recurrent chest infections over several years. Episodes were characterised by cough and green sputum without haemoptysis. There was no history of chest pain, shortness of breath, fever, night sweats or weight loss. She had received several courses of antibiotics for this from her general practitioner. Her past medical history included whooping cough as a child and hysterectomy at age 40 years, for reasons unknown. She had smoked 10 cigarettes per week since her teenage years and denied any alcohol intake. There were no pets at home or any history of recent travel.

\section{Examination}

The patient was comfortable at rest, with no cyanosis, clubbing, leg oedema or lymphadenopathy. Pulse rate was 88 beats per min and regular, blood pressure 155/85 mmHg and her jugular venous pressure was normal. Chest examination was normal except for an occasional wheeze. Cardiovascular examination revealed a soft systolic murmur at the apex with normal heart sounds. The rest of her examination was normal.

\section{Investigations}

Initial blood results showed: white blood cell count $4.1 \times 10^{9}$ per $\mathrm{L}, \mathrm{Hb} 13 \mathrm{~g}$ per $\mathrm{dL}$, platelets $319 \times 10^{9}$ per $\mathrm{L}$, glucose $5 \mathrm{mmol}$ per $\mathrm{L}$, thyroidstimulating hormone $1.76 \mathrm{U}$ per $\mathrm{mL}$ and normal liver and renal functions. Immunoglobulin (Ig) levels were as follows: IgG 11.6 (7-14) U per mL, IgA $3.13(0.75-4) \cup$ per $\mathrm{mL}$ and IgM 0.4 (0.31.7) $\mathrm{U}$ per $\mathrm{mL}$.

Sputum culture showed no growth. Electrocardiogram (ECG) showed sinus rhythm.

Spirometry results were as follows: forced expiratory volume in one second (FEV1) $1.26 \mathrm{~L}$ (60\% predicted); forced vital capacity $1.75 \mathrm{~L}$ (65\% pred); and FEV1/FVC 72\%.

Figure 1 shows chest radiography.
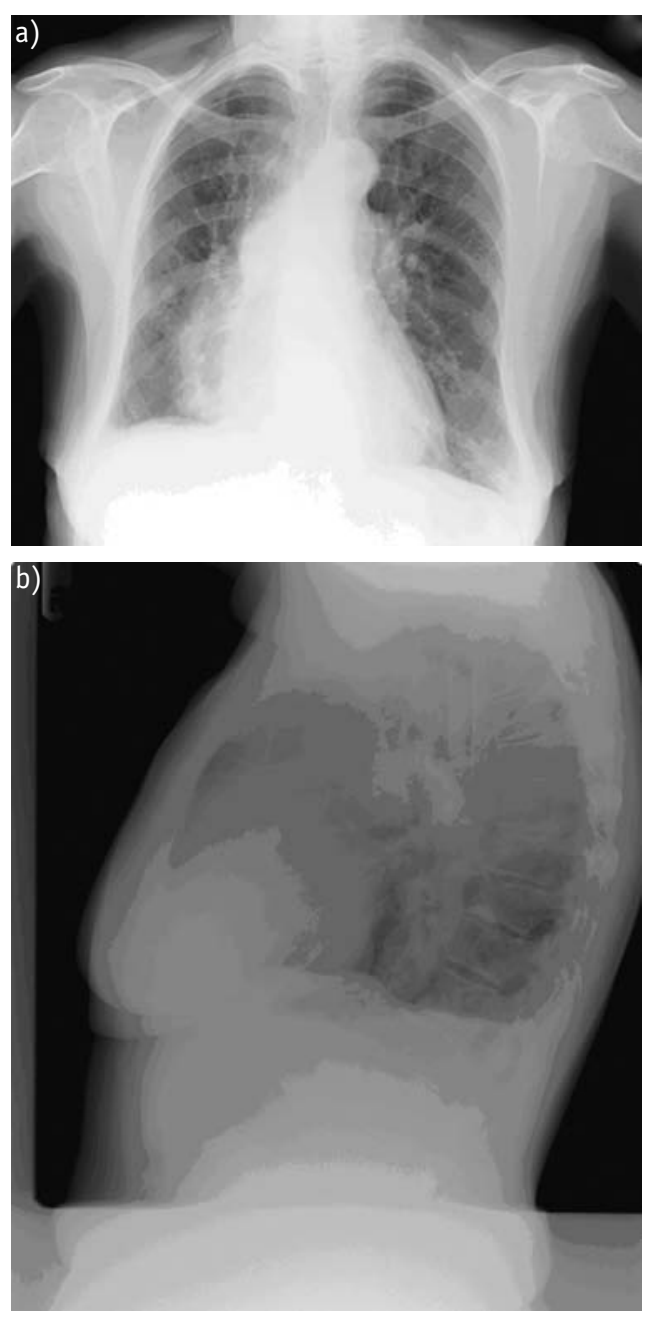

Figure 1

Chest radiography.

Task 1

Interpret the chest radiographs.

\section{Task 2}

What is your clinical diagnosis? a. Pneumonia in view of recurrent infection.

b. Tumour in view of smoking history. c. Developmental anomalies in view of peculiar chest radiography findings.
K. Nandakumar

I. Ahmed

R. Bhutt

\section{resnirator}

Dept of Respiratory Medicine, Sandwell General Hospital, West Midlands, UK.

\section{Correspondence}

K. Nandakumar

Dept of Respiratory Medicine Sandwell General Hospital

Lyndon

West Bromwich

West Midlands

B71 4HJ

UK

E-mail:kabnanda@gmail.com 


\section{Answer 1}

Prominent right hilum. III-defined curvilinear shadow in the right paracardiac region.

\section{Answer 2}

c.

Bronchoscopy showed no upper lobe bronchus. There were three openings from the bronchus intermedius and no apical segment division. No endobronchial lesion was seen.

Figure 2 shows the results of computed tomography (CT) scanning.

Figure 2 CT scans.
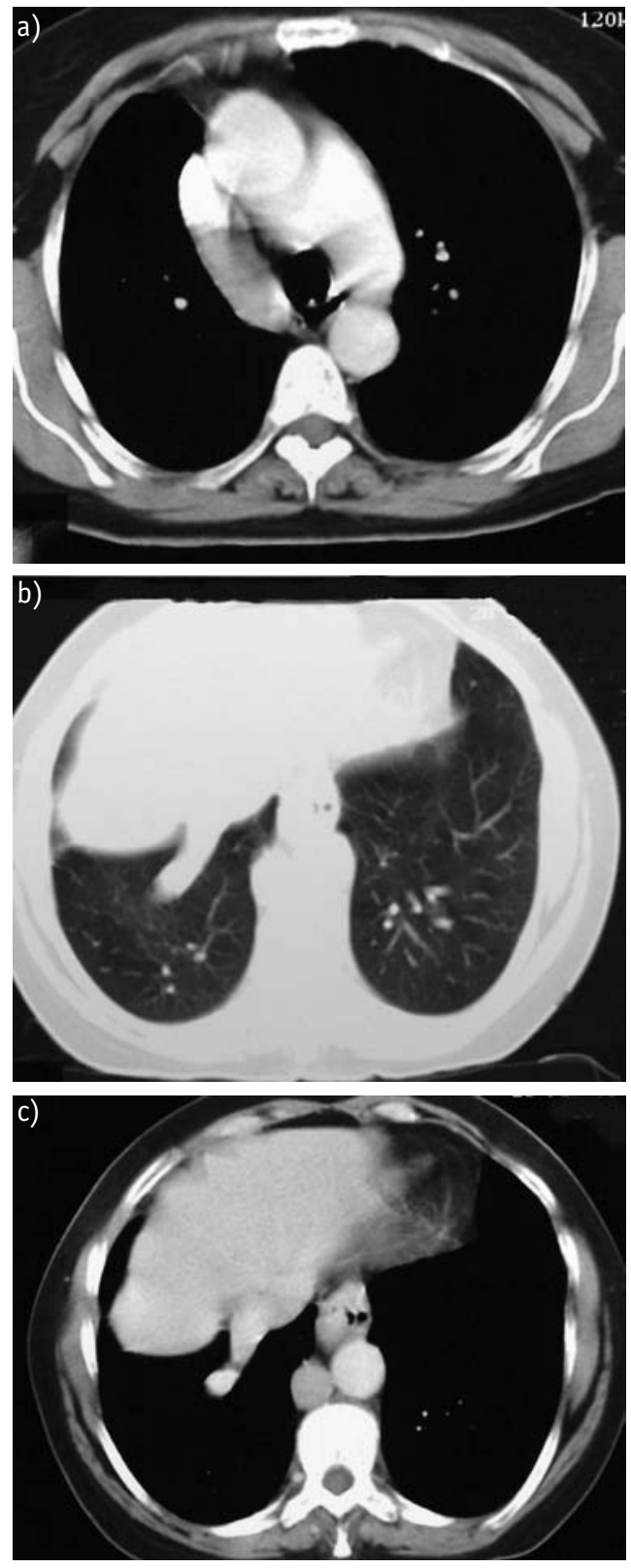

Task 3

Interpret the CT scans.
Answer 3

The right lung is smaller with a slightly displaced mediastinum to the right. A large pulmonary vein can be seen in the right lung, draining into the venous system below the diaphragm forming the inferior vena cava (IVC), which is consistent with Scimitar syndrome. In addition, the right upper lobe bronchus is absent and there is trifurcation of the right bronchus intermedius (not visualised in these images). 
A transoesophageal echocardiogram revealed morphologically normal valves with mild mitral regurgitation and trivial tricuspid regurgitation. The interatrial septum was intact. The right heart was not dilated and there was no evidence of intracardiac shunt.

\section{Discussion}

Scimitar syndrome is a rare but well-documented congenital anomaly, first described in 1836 by CHASSINAT [1] and COOPER independently [2]. The term "scimitar" was not used until 1956, when HASALAZ et al. [3] described the appearance of an anomalous vein whose curvilinear opacity on radiography resembled a Turkish sword. However, it was NelLL et al. [4], in 1960, who coined the term Scimitar syndrome [5].

Scimitar syndrome is also known as congenital venolobar syndrome and it consists of partial anomalous pulmonary venous drainage from the right lung into the IVC, partial agenesis or hypoplasia of the right lung, dextrocardia and anomalous systemic arterial supply especially to the right lower lobe. Other features include hypoplastic or absent pulmonary artery, bronchopulmonary sequestration and cardiac anomalies (atrial or ventricular septal defect, coarctation of aorta, pulmonary stenosis, tetralogy of fallot) $[6,7]$.

This anomaly occurs as the result of abnormal development of the right lung bud early in embryogenesis. It tends to most frequently involve the right lung, for unknown reasons, with rare reports of left lung involvement. It occurs more commonly in females, with occasional familial occurrence. The clinical presentation is quite variable, being asymptomatic to florid heart failure. Dupuls et al. [8], in their review of 122 adult patients, showed recurrent pneumonia as the most common presentation, occurring in 38 patients, exertional breathlessness in 23 patients, deformity of thorax in eight and haemoptysis in seven.

In the adult form, which is defined as those patients in whom the syndrome is detected after the first year of life, clinical examination may be entirely normal. ECG may show right ventricular strain. Echocardiography, apart from identifying associated anomalies, may also be helpful in establishing the diagnosis. However, this can miss about 33\% of patients [9]. CT, cardiac catheterisation, and magnetic resonance imaging with three-dimensional magnetic resonance angiography are more rewarding $[10,11]$.

One-quarter of cases are symptomatic in the newborn, presenting as respiratory or cardiac failure needing corrective surgery. Although repair of the anomalous venous return or ligation of collaterals is the procedure of choice, pneumonectomy has also shown similar early and late results. Surgery is indicated when the right-to-left shunt is $>2: 1[12,13]$. Sometimes patients present with an incidental radiological finding with no symptoms. They require no intervention.

The current patient presented with recurrent chest infections and since there was no significant shunt, she was managed conservatively with antibiotics.

\section{References}

1. Chassinat R. Observation d'anomalies remarquables de l'appareil circulatoire, avec hepatocele congéniale, n'ayant donné lieu pendant la vie a àucum symptome particulier. Arch Gen Med 1836; 11: 80-91.

2. Cooper G. Case malformation of the thoracic viscera: consisting of imperfect development of right lung and transposition of heart. London Med Gaz 1836; 18: 600-602.

3. Halasz NA, Halloran $K H$, Leibow AA. Bronchial and arterial anomalies with drainage of right lung into inferior vena cava. Circulation 1956; 14: 826-846.

4. Neill CA, Ferencz C, Sabiston DC, Sheldon $H$. The familial occurrence of hypoplastic right lung with systemic arterial supply and venous drainage. "Scimitar syndrome". Bull Johns Hopkins 1960; 107: 1-15.

5. Mulligan ME. History of scimitar syndrome. Radiology 1999; 210: 288-290.

6. Huddleston SG, Exil V, Canter CE, Mendeloff EN. Scimitar syndrome presenting in infancy. Ann Thorac Surg 1999; 67: 154-160.

7. Gikonyo DK, Tandon R, Lucas RV, Edwards JE. Scimitar syndrome: report of four cases. Pediatr Cardiol 1986; 6: 193-197.

8. Dupis C, Haraf LAC, Breviere GM, Abou P. "Infantile" form of scimitar syndrome with pulmonary hypertension. Am J Cardiol 1993; 71: 1326-1330.

9. Wong ML, McCrindle BW, Mota C, Smallhorn JF. Echocardiographic evaluation of partial anomalous pulmonary venous drainage. J Am Coll Cardiol 1995; 26: 503-507.

10. Huebsch $P$, Neuhold A, Mayr H, Glogar D. Anamalous pulmonary venous drainage shown by duplex sonography, computed tomography, and plain radiography. Thorax 1989; 44: 63-65.

11. Hornero F, Canovas S, Estornell J, Cervera V. Scimitar syndrome: multislice computer tomography with three-dimensional reconstruction. Interactive Cardiovasc Thorac Surg 2003; 2: 341-344.

12. Najm HK, Williams WG, Coles JG, Rebeyka IM, Freedom RM. Scimitar syndrome: twenty years' experience and results of repair. J Thorac Cardiovasc Surg 1996; 112: 1161-1169.

13. Brown JW, Ruzmetov M, Minnich DJ. Surgical management of scimitar syndrome: an alternate approach. J Thorac Cardiovasc Surg 2003; 125: 238-245. 